This item was submitted to Loughborough's Research Repository by the author.

Items in Figshare are protected by copyright, with all rights reserved, unless otherwise indicated.

\title{
Crack initiation and propagation in ductile specimens with notches: experimental and numerical study
}

\section{PLEASE CITE THE PUBLISHED VERSION}

http://dx.doi.org/10.1007/s00707-015-1425-0

\section{PUBLISHER}

(c) Springer-Verlag Wien

\section{VERSION}

AM (Accepted Manuscript)

\section{PUBLISHER STATEMENT}

This work is made available according to the conditions of the Creative Commons Attribution-NonCommercialNoDerivatives 4.0 International (CC BY-NC-ND 4.0) licence. Full details of this licence are available at: https://creativecommons.org/licenses/by-nc-nd/4.0/

\section{LICENCE}

CC BY-NC-ND 4.0

\section{REPOSITORY RECORD}

Schiavone, Alessandro, Gayan A. Abeygunawardane-Arachchige, and Vadim Silberschmidt. 2019. "Crack Initiation and Propagation in Ductile Specimens with Notches: Experimental and Numerical Study". figshare. https://hdl.handle.net/2134/19460. 


\title{
Crack initiation and propagation in ductile specimens with notches: experimental and numerical study
}

\author{
Alessandro Schiavone*, Gayan Abeygunawardana-Arachchige, Vadim V. Silberschmidt \\ Wolfson School of Mechanical and Manufacturing Engineering \\ Loughborough University, LE11 3TU, Loughborough, UK
}

*Corresponding author: Alessandro Schiavone; Email: A.Schiavone@LLboro.ac.uk

\begin{abstract}
Failures of components and structures are often related to the presence of notches of different shapes. Damage modelling techniques have been proven capable of modelling the crack initiation and propagation in ductile materials (such as Al alloys). The Gurson-Tvergaard-Needleman (GTN) method and Extended Finite Element Method (XFEM) are compared against original experiments to study the crack initiation and propagation processes in aluminium specimens with different notch shapes (V-shape, U-shape and square). Two regimes are considered in this study: quasi-static and impact uniaxial tensile loading. Results show that the load-bearing capability predicted with the two methods is somewhat lower compared to experiments; still, the crack shapes were predicted correctly, with the exception of the square-notch case, for which XFEM was unable to predict the correct shape due to limitations in the model formulation. This study provides information useful for design of components with stress raisers that are exposed to different loading regimes and shows limitations in both the GTN- and XFEM-based approaches that in many cases underestimate the loadbearing capacity
\end{abstract}

Keywords: Ductile damage; GTN model; XFEM; Notched specimens; Finite element

\section{Introduction}

Failure of many components and structures is related to cracks initiated at locations of stress raisers, often related to notches of various shapes and dimensions. One of the typical examples is a screen used in shakers for separation of particulate matter. Screens have patterns of perforation (holes) with different geometry and, though made of ductile materials, fail as a result of crack emanating from these holes. A dynamic regime of loading as a result of repetitive impact of particles, defines specific features of this process.

Damage modelling techniques have been widely used to model crack initiation and propagation in ductile materials, such as aluminium alloys and stainless steel. Ruzicka et al. (2012) showed that by calibration of damage parameters against experimental uniaxial tensile test data, damage modelling can predict force-displacement curves in good accordance with the experiments for different notched specimens, i.e. tensile bar, notched bar and butterfly specimens. Another work by Zuo et al. (2003) studied a failure process in ductile materials and implications for its prediction, based on a relationship between the failure initiation and the stress constraint. Their work demonstrated that a two-parameter model is capable to predict the failure of ductile materials by modelling the growth and nucleation of voids. These mechanisms can be described using several approaches, two of which are used in this paper 
The first - a Gurson-Tvergaard-Needleman (GTN) method - is based on simulation of softening and failure of ductile material based on the introduced approximations for void nucleation, growth and coalescence in their microstructure, into the models of the plastic flow, hardening behaviour and failure (Gurson, 1977; Tvergaard, 1980; Needleman et al., 1984). The GTN method was employed, for instance, to simulate the fracture in aluminium round bars (Anvari et al., 2007) and compared with experimental results for both quasi-static and dynamic loading conditions. These results showed that the simulations provided reliable account for the rate dependency and that the diameter reduction of the specimens was also predicted properly, even though the final diameter differed from that in experiments. Additionally, Xue et al. (2010) conducted a calibration study of an extended Gurson constitutive model to predict the processes of ductile fracture in steel, which demonstrated that after proper calibration this model could predict the damage initiation and propagation in a ductile structural alloy under a wide range of stress states. This was achieved by calibrating the model with three types of tests: uniaxial tension, mode-I and mode-Il cracking. The GTN method was also employed to simulate ductile fracture in steel specimens with notches under a high stress-triaxiality regime (Kiran et al., 2013), successfully predicting the ductility of structural components in the case of bars with holes, a plate with reduced section and plates with holes.

Ductile fracture can also be modelled with a cohesive-crack model, in which the propagation of the crack is governed by a traction-separation law across the crack faces at the tip. When the crack path is not known, this method can be used within the framework of Extended Finite Element Model (XFEM), which simulates the discontinuity in the displacement field along the crack path (Moës, 2002). Compared with other schemes, for instance cohesive-zone elements, this method allows the crack to grow within the elements and along their interfaces, a feature that considerably reduces the mesh dependency of results (Moës, 1999). Although this method has recently become very popular for the modelling of brittle fracture, the validity of XFEM for the modelling of crack initiation and propagation in ductile materials is an open subject.

Seabra et al. (2012) compared the XFEM method for B-bar and F-bar formulations with other competing methods, i.e. the enhanced strain formulation. The study showed that XFEM can handle efficiently problems with ductile materials that would require a very high computational effort if solved with more traditional techniques. For example, XFEM combined with Lemaitre ductile damage modelling has been used to solve the problem of fracture in ductile metals (Seabra et al., 2013) in the case of double-notched specimens. Results showed that XFEM can deal with ductile fracture without additional material parameters, without knowing the location of the crack and a considerably reduced mesh dependency, compared to traditional damage models. A further study of application of XFEM for the crack growth in ductile materials was conducted by Kumar et al. (2013), who applied this method to solve of two problems: compact tension and three point bending. The obtained loaddisplacement curves showed a very good agreement with the literature data for both type of specimens, demonstrating that XFEM is an effective tool for the modelling of stable crack growth in ductile materials.

The response of ductile materials to impact loading is important for a large number of applications, especially manufacturing, e.g. high speed blanking and hole flanging processes. This regime covers also a wide range of loading cases - hypervelocity impact, blast loading, jet impact, projectile penetration, dropped-object loading, structural crushing and so on. As a result, multiple studies have been conducted for a wide range of materials under these conditions. An impact-test approach was used to study the impact behaviour of monolithic materials (Ali et al., 2011). Recently conducted studies employed Charpy impact tests for the measure of toughness under different temperature conditions for rectangular hollow sections (Sun et al., 2014). Influence of notch severity on the impact behaviour of an Al-alloy was studied by Champlin et al. (1999) with notch angles of $45^{\circ}, 75^{\circ}$ and $90^{\circ}$. The studied samples were notched only on one side and a standard Charpy impact test was conducted. Still, a dynamic response to impact loading, including fracture initiation, crack propagation 
and crack shapes, was studied insufficiently for standard notched specimens made of ductile metals (i.e. aluminium).

The aim of this study is to compare different strategies for modelling of crack initiation and propagation in ductile materials by validation against experimental results. In the first part of this work, the GTN and XFEM methods employed in numerical simulations of aluminium specimens with three different types of notches: V-shape, U-shape and square - are compared against the original results from quasi-static uniaxial tension experiments. The force-displacement curves obtained in the experiments and with numerical simulations are compared as well as the crack shapes. In the second part, analyses of the same specimens were conducted under dynamic loading conditions. For these analyses, GTN and XFEM were adopted, monitoring force-time curves and crack shapes.

\section{Methodology}

\subsection{Experimental setup}

Experiments were performed to study the crack initiation and propagation in aluminium specimens in the presence of macroscopic notches. The specimens were prepared according to standard ASTM E8-13a for tension testing of metallic materials. The effect of three different notches was studied - Vshape, U-shape and square; the notches were designed according to standard ASTM E399-12 for the measurement of the strain fracture toughness of metallic materials. The used specimen and notches with respective dimensions are shown in Figure 1. The aluminium alloy employed to manufacture the specimens was Al 1050A (EN AW-1050A-H14), which is 99.5\% aluminium, strain hardened to halfhard temper.

All the specimens were machined from raw aluminium sheets using a wire cutting technique; the obtained dimensions of the specimens were then analysed a using Smart-scope 200 automatic measuring machine. It uses a video measurement system, which - along with 3 axis of movement allows very accurate measurements to be taken of parts placed onto the machine bed. The measurements were taken under $32.5 \%$ magnification and $44 \%$ lighting which allowed any deviations from the actual dimensions to be detected. Analysis of the images was performed by means of equally spaced points $(0.02 \mathrm{~mm}$ of distance) automatically detected by the software on the border of the specimens. This test ensured that the dimensions of the specimens were in good agreement with those specified for machining with a tolerance of $0.05 \mathrm{~mm}$.

Uniaxial tensile tests with the manufactured specimens were performed according to standard ASTM E8-13a, an Instron 3369 universal testing machine, with a maximum load of $5 \mathrm{kN}$. Furthermore, the tensile tests were performed at three different extension rates: i.e. $1 \mathrm{~mm} / \mathrm{min}, 0.5 \mathrm{~mm} / \mathrm{min}$ and 5 $\mathrm{mm} / \mathrm{min}$, to ensure that there was no rate dependency on our results. Each test was repeated 5 times for all the three extension rates, with a total number of 15 tests for each type of specimen.

\subsection{GTN technique}

GTN is a method capable to describe the damage-induced softening of the material. It is based on theory of plasticity of materials with voids and simulates micro-void nucleation, growth and failure in terms of the effective porosity factor $f^{*}$, assuming isotropic behaviour of the material (Gurson et al., 1977; Tvergaard, 1982; Needleman et al., 1984)

The constitutive equation (Abaqus Documentation, 2013) is given by

$$
\Phi\left(\sigma_{y}, f^{*}\right)=\left(\frac{q}{\sigma_{y}}\right)^{2}+2 q_{1} f^{*} \cosh \left(-\frac{3}{2} \frac{q_{2} p}{\sigma_{y}}\right)-\left(1+q_{3} f^{* 2}\right)
$$


where $q=\sqrt{3 / 2 s: S}$ is von Mises stress, $S$ is the deviatoric stress tensor, $p$ is the hydrostatic pressure, $\sigma_{y}$ is the yield stress, $q_{1}, q_{2}$ and $q_{3}$ are arbitrary GTN model parameters.

The effective porosity $f^{*}$ is given by the following equation:

$$
\left\{\begin{array}{cl}
f & \text { if } f \leq f_{c} \\
f_{c}+\frac{\bar{f}_{f}+f_{c}}{f_{f}-f_{c}}\left(f-f_{c}\right) & \text { if } f_{c}<f<f_{f} \\
\bar{f}_{f} & \text { if } f \geq f_{f}
\end{array}\right.
$$

where $f_{C}$ is the magnitude of void volume fraction that triggers their coalescence in the material and $\bar{f}_{f}=\left(q_{1}+\sqrt{q_{1}{ }^{2}-q_{3}}\right) / q_{3}$ is the void volume fraction at which the material losses its load-bearing capacity.

At first, the GTN parameters were found in the literature (He, 2011), where used for aluminium specimens then they were adjusted by varying the total void volume fraction at failure $\left(f_{f}\right)$ and the critical void volume fraction $\left(f_{c}\right)$ so that the displacement at failure matched our experimental results. The parameters for the GTN that showed the best fit of the force-displacement curve for the studied material are shown in Table 1.

\subsection{XFEM technique}

Displacement approximation in XFEM is based on enrichment of the finite element (FE) approximation with discontinuous functions. The displacement of the enriched nodes is given by the following equation (Abaqus Documentation, 2013):

$$
u=\sum_{i=1}^{n} N_{i}(x)\left[u_{i}+H(x) a_{i}+\sum_{\alpha=1}^{4} F_{\alpha}(x) b_{i, \alpha}\right]
$$

where $n$ is the total number of nodes, $N_{i}(x)$ is the shape function of the node $i, H(x)$ is the jump enrichment function, $F_{\alpha}(x)$ is the tip enrichment function, $b_{i, \alpha}$ are additional degrees of freedom and $i$ and $\alpha$ are the sets of all nodes and the tip enriched nodes respectively.

A traction-separation law was used to model damage in XFEM, based on the Maximum Principal Stress criterion for the crack initiation, while the damage evolution was modelled based on the definition of the facture energy. Similarly to the case of GTN the parameters were calibrated based on the obtained experimental results, in order to predict the correct displacement at failure in the case of the uniaxial tension of the specimen without notch. The XFEM parameters that produced the best results are given in Table 2 .

\section{$2.4 \quad$ Finite-element modelling}

The geometry of all studied specimens was reproduced in Abaqus finite-element software, according to the dimension and shapes defined in our experimental work. The specimen without notch was modelled as a shell part, while those with notches were modelled as square shell parts of a gauge length, with dimensions of $1 \mathrm{~mm}$ in thickness and $20 \mathrm{~mm}$ in length and width. A symmetry boundary condition was used for the line of the specimen's main axis, reducing thus computational efforts. For the GTN, the specimen with a square notch was also modelled as a square shell part, with dimensions of $1 \mathrm{~mm}$ and $40 \mathrm{~mm}$ to cover the entire width of the modelled specimens; this was due to the asymmetric crack path expected for this notch shape. All the notches were modelled based on the shape and dimensions of the experimental specimens - shown in Figure 1. The notched parts with 20 
$\mathrm{mm}$ in length and width were modelled with a single notch on the right edge of the part, whilst the square notch specimen with dimensions of $40 \mathrm{~mm}$ had two notches on both edges of the part.

For the GTN-based modelling, the Abaqus/Explicit solver was used to perform the analyses. The parts were meshed with around 10000 elements for the notched specimens, with hexahedral 4-node shell elements with reduced integration and plain-stress formulation. The Abaqus/Standard solver was employed for the XFEM analyses; the parts were meshed using some 5000 elements of the same type. The reason behind different mesh densities is due to the fact that GTN modelling is based on element deletion, which makes it strongly mesh dependent compared to XFEM. The used mesh and geometry of the models are shown in Figure 2.

Material properties for Al 1050a were extracted directly from the data obtained with the uniaxial tensile test performed on specimens without notch. Its Young's modulus was calculated to be $70 \mathrm{GPa}$, the Poisson's ratio 0.33 , yield stress $85 \mathrm{MPa}$ and the plastic region was fitted with a multi-linear curve based on the points of our experimental tests. These data were introduced into the FE models.

For the quasi-static uniaxial tension simulation, boundary conditions (BCs) were used on the bottom and top of each specimen, the bottom edge was fixed in the $Y$ direction, whilst the top specimen had a displacement $B C$ in the $Y$ direction, which magnitude depended on the simulation, i.e. $20 \mathrm{~mm}$ for the specimen without notch and $2 \mathrm{~mm}$ for the specimens with notches. A symmetry BC was applied to the left edge of the $20 \mathrm{~mm}$ notched specimens. Since in the cases of the specimen without notch and the $40 \mathrm{~mm}$ square-notch part the symmetry boundary condition cannot be applied, the nodes on their bottom and top edges were also constrained in the $X$ direction to avoid a rigid-body motion. Figure 3 illustrates the BCs used for the case of $20 \mathrm{~mm}$ and $40 \mathrm{~mm}$ specimens.

In the impact loading analysis, a hammer of Resil impactor used in the tests was introduced into transient simulations employing a 3D arrangement as shown in Figure 4a. Still, a 2D plane-stress formulation is adequate for the modelling needs. The surface energy $\gamma$ of the aluminium was considered $1500 \mathrm{~J} / \mathrm{m}^{2}$, equal to half of the fracture energy used for the XFEM model (Table 2). The nominal cross section was also calculated for the notched specimens. The total energy required to fracture the sample should be given in the form of kinetic energy of the impactor. Based on the energy conservation, the velocity of the impactor was calculated as $361 \mathrm{~mm} / \mathrm{s}$ to completely fracture the specimen. The kinetic energy carried by the impactor can be transferred to the specimen efficiently with the rigid body impactor. Displacements at the fixed edge of the specimen were constrained, with regard to rotation and displacement along the $X$ and $Y$ directions (Figure 4b), and the calculated velocity was imposed to the assigned reference point on the impactor.

A typical stress pattern obtained with XFEM analysis of specimen with V-notch in both quasi-static and impact loading conditions shows that in dynamic loading simulation the von Mises stress is more localised (Figure 5b) compared to quasi-static simulations (Figure 5a). Examples of distribution of voids - in terms of void volume fraction - in GTN-based simulations of the specimen with the U-shape notch for quasi-static and impact loading (Figures $5 \mathrm{c}$ and $5 \mathrm{~d}$, respectively) demonstrate similar patterns, with a concentration of voids in the vicinity of the crack tip and around the point of crack initiation.

\section{Results and Discussion}

\subsection{Specimen without notch}

The simulation involving the dog bone specimen without notch was used to calibrate our material model, especially the GTN and XFEM parameters against the experimental results. Figure 6 shows the force-displacement curve curves for the specimen without notch, obtained in the experimental study as well as with XFEM and GTN simulations. 
A comparison of these results demonstrates that the elastic and plastic material behaviours were correctly predicted in both models. Still, XFEM modelling exhibit no softening behaviour, which leads to a small overestimation of the force (some 5.3\%) when the specimen reaches the point of complete fracture. The GTN model was capable to predict the force at all times with a maximum error of $0.2 \%$.

The GTN and XFEM models predicted a displacement at complete failure at respectively $3.0 \mathrm{~mm}$ and $2.0 \mathrm{~mm}$, whilst the experiments showed that complete failure occurred at around $3.4 \mathrm{~mm}$. In both models, this point was extremely sensitive to the used parameters, making it difficult to find their suitable set. However, under-estimation of the failure can contribute to a safety factor, making design more conservative. This led to a choice of parameters that under-predicts the failure.

\subsection{V-shape Notch}

The force-displacement curve for the uniaxial tension of $V$-shape notched specimen is shown in Figure $7 \mathrm{a}$. The results demonstrate that GTN and XFEM predicted a maximum force of respectively $2560 \mathrm{~N}$ and $2850 \mathrm{~N}$, while the experiments resulted in $3490 \mathrm{~N}$ at the peak of the curve. Apparently, both GTN and XFEM resulted in much earlier onset of damage and swifter crack propagation under loading.

The displacement at complete failure was predicted earlier by the GTN model, with $0.38 \mathrm{~mm}$ compared with $0.54 \mathrm{~mm}$ in the experiments. The XFEM model estimated this value correctly, showing compete fracture at $0.56 \mathrm{~mm}$ of expansion. Also, consistently with the results for the specimen without notch, the displacement at which the crack initiates was under-predicted by the GTN model. The crack initiates in the local maximum of the curve, which was $0.41 \mathrm{~mm}$ in the experiments, but predicted at $0.23 \mathrm{~mm}$ for the GTN method and $0.39 \mathrm{~mm}$ for XFEM.

Both models provided correct paths of crack propagation: from the tip of the notch straight through the specimen, which was in accordance with the experimental results. The crack evolution was consistent for GTN and XFEM simulations (Figure 7b), with the speed of the crack propagation accelerating with the applied displacement; this process is smoother in the XFEM model.

Main simulation results for this notch under dynamic loading conditions are shown in Figures 8 and 9 . The force-time curve (Figure 8a) demonstrate that in both GTN and XFEM simulations, the force increased rapidly at $0.014 \mathrm{~s}$, at the moment of the initial contact of the specimen by the impactor, and stabilisde for roughly $0.006 \mathrm{~s}$ with an average maximum value of $7000 \mathrm{~N}$, until dropping at $0.020 \mathrm{~s}$, when there is complete failure of the specimen. Those forces were much higher than those in quasistatic loading conditions. The crack growth is shown in Figure 8b; the XFEM method predicted that the crack growth starts earlier than in GTN, with similar temporal evolution. The crack shape (Figure 9) in both methods has the same characteristics, initiating at the tip of the notch and propagating straight through the specimen until full separation occurs - as in non-dynamic cases.

\subsection{U-shape Notch}

Results for the U-shape notch are shown in Figure 10 and 11, respectively for quasi-static tension and impact loading. Once again the maximum forces were lower in the results obtained with the GTN and XFEM simulations when compared with the experimental data (Figure 10a). Simulations showed a maximum force of $3110 \mathrm{~N}$ and $2818 \mathrm{~N}$, respectively for the GTN and XFEM methods; the experimental results showed a force of $3490 \mathrm{~N}$.

The type of notch affected the realisation of crack propagation: GTN and XFEM showed a displacement at complete failure of $0.6 \mathrm{~mm}$ and $0.8 \mathrm{~mm}$, respectively. They are significantly larger than those in the case of $\mathrm{V}$-notch, although the thinnest cross-sectional area was the same in all the notched specimens. The value obtained experimentally $-0.6 \mathrm{~mm}$ - was consistent only with results from the GTN model. It has to be noted that the U-shape notch is the only one with no sharp corners among the three cases; this means that the stress is not localised in a specific point of the surface. 
This fact lead to an over-estimation of the point of fracture initiation in case of GTN, which in fact predicted this at $0.51 \mathrm{~mm}$. In the case of XFEM, the fracture initiation was predicted at $0.40 \mathrm{~mm}$, compared to $0.42 \mathrm{~mm}$ in the experiments. This is an important point, since, based on our calibration, the crack always initiated earlier than in the experiments.

The crack path was again predicted correctly by our models, with the crack initiating from the middle of the U-shape notch and propagating straight through the whole specimen, just as was observed in the tests. This was caused by mesh sensitivity of element-deletion methods (such as GTN) and could be solved by using a very regular or very fine mesh. The growth of the crack against the applied displacement (Figure 10b) showed that both the GTN and XFEM cracks grow similarly, with the XFEM crack growing earlier compared with GTN.

Results from the dynamic loading simulations showed that the force-time curve (Figure 11) followed a similar pattern for both GTN and XFEM techniques. The force increased to a maximum of around $4500 \mathrm{~N}$ in both cases and dropped rapidly (Figure 11a). The crack paths for both simulations were close to those in quasi-static loading and the crack evolution over time was similar for both methods (Figure 11b).

\subsection{Square notch}

Results for the square-notch specimen showed that in both cases the force-displacement curve (Figure 12a) exhibited a lower local maximum at a force of $2990 \mathrm{~N}$, compared to the experimental results $(3384 \mathrm{~N})$; this difference was $11.6 \%$. In this GTN simulation, the specimen was modelled with two notches, contrarily to all the other cases shown in this study, in which only half specimen was considered due to existing symmetry.

The displacement at complete failure, however, was over-predicted by the GTN model, showing final fracture at $0.70 \mathrm{~mm}$ of expansion. The XFEM model exhibited a result $(0.90 \mathrm{~mm})$ which was also higher compared to experiments $(0.60 \mathrm{~mm})$. In the case of GTN, the crack initiation was predicted at a displacement of $0.40 \mathrm{~mm}$, while in XFEM this point was shown at $0.50 \mathrm{~mm}$, compared with the 0.42 $\mathrm{mm}$ of experimental results.

Once again XFEM predicted the earlier crack initiation and propagation with the GTN method predicting a significantly longer stage of crack slow growth followed by a rapid final rupture (Figure 12b). The experimental results for the square notch (Figure 13a) showed that in this case the crack path was not as predictable as for the other notch geometries. In fact, the stress concentration pattern showed that stresses were concentrated in the four corners of the two notches. Due to this, the cracks initiate straight from two corners along the diagonal and they merge together diagonally in the middle of the specimen. This path of the crack could only be simulated with GTN (Figure 13b) in the case when both the left and right notches of the specimen were included to the model. The XFEM technique (Figure 13c) does not have the feature of joining two cracks together; hence it was impossible for this model to reproduce the correct crack path in this case.

Under impact loading conditions, force signals (Figure 14a) demonstrated that the force increased to the value of about $6000 \mathrm{~N}$ and remained constant nearly until the complete fracture of the specimen. The evolution of the crack length over time (Figure 14b) shows that the crack grows suddenly after $0.015 \mathrm{~s}$ according to the results of both methods. Also, the dynamic loading affected the crack propagation scenario: the crack was generated on the two top directly opposite corners of the notches, as shown in Figure 14c, and propagated straight towards each other to connect together in the middle of the specimen. The lower corners of the notches exhibited no fracture at all. Results from XFEM simulations were consistent with this pattern of main crack (Figure 14d), the only difference being initiation of secondary cracks at lower corners. 


\section{Conclusions}

In this study, the XFEM and GTN techniques implemented in the FE models were compared to experimental results in order to assess their capabilities in analysis of crack initiation and propagation in a ductile material. The simulations were used to study the problems of quasi-static uniaxial tension and dynamic impact loading of notched aluminium 1050a specimens, for three different notch shapes - V-shape, U-shape and square.

Despite the relative simplicity of the problem, results showed that when the whole dog bone specimen was simulated, the force evolution was accurately predicted by the GTN and XFEM models. However, the load-bearing capacity was under-estimated when the methods applied to notched specimens.

The crack evolution was better described with XFEM in the case of notches with sharp corners, such as the V-shape notch, whilst the GTN model performed better in the case of U-shape notch. In the case of V-shape and square notches, the maximum stresses were localised around those corners, making the prediction of the crack initiation and the displacement at complete fracture easier for XFEM. The U-shape notch, which does not exhibit any sharp corner, showed that the models may over-estimate the point of crack initiation and lead to failure at displacements that are higher than in the experimental results.

The XFEM model proved to be reliable in predicting the shape of the cracks only when the cracks were symmetric and, therefore, offered the chance to simulate only half of the specimen. In the case of the square notch, with two propagating crack merging, the shape was impossible to predict due to the limitations in the XFEM formulation. GTN method, however, proved to be more powerful in this regard, with the only limitation of being highly mesh sensitive and requiring a higher computational effort to run.

Under dynamic loading, the GTN and XFEM methods offered consistent results. In the case of impact, the crack path for the square notch was different from that for the quasi-static conditions and predicted consistently by both methods. Generally, XFEM technique exhibited significant difficulties in terms of stability of the simulation, especially with the U-shape and V-shape notches. Still, the obtained force signals and crack shapes correlated with the results obtained with GTN models.

This study provides some information useful for design of components with stress raisers that are exposed to different loading regimes. Still, both the GTN- and XFEM-based approaches demonstrated some limitations in predictions not only of the advanced stages of fracture evolution but also the onset of crack propagation. In many cases they underestimate the respective parameters.

\section{Acknowledgement}

The research leading to these results has received funding from the European Union Seventh Framework Programme (FP7/2007-2013) under grant agreement No. PIAPP-GA-284544-PARM-2.

\section{References}

1. Abaqus Documentation, Version 6.13, Dassault Systèmes, Vélizy-Villacoublay, France (2013)

2. Anvari M., Liu J., Thaulow C.: Dynamic ductile fracture in aluminum round bars: experiments and simulations. Int. J. Fract. 143, 317-332 (2007)

3. Champlin J., Zakrajsek J.: Influence of notch severity on the impact fracture behavior of aluminum alloy 7055, Mater. Design 20, 331-341 (1999) 
4. Gurson A.L.: Continuum Theory of Ductile Rupture by Void Nucleation and Growth: Part 1 Yield Criteria and Flow Rules for Porous Ductile Media. J. Eng. Mat. Tech. 99, 2-15 (1977)

5. He M., Li F., Wang Z.: Forming Limit Stress Diagram Prediction of Aluminum Alloy 5052 Based on GTN Model Parameters Determined by In Situ Tensile Test. Chin. J. Aeronaut. 24, 378-386 (2011)

6. Kiran R., Khandelwal K.: Gurson model parameters for ductile fracture simulation in ASTM A992 steels. Fatigue Fract. Eng. M. 37, 171-183 (2012)

7. Kumar S., Singh I.V., Mishra B.K.: Numerical Investigation of Stable Crack Growth in Ductile Materials Using XFEM. Procedia Eng. 64, 652-660 (2013)

8. Moës N., Belytschko T.: Extended finite element method for cohesive crack growth. Eng. Fract. Mech. 69, 813-833 (2002)

9. Moës N., Dolbow J., Belytschko T.: A finite element method for crack growth without remeshing. Int. J. Numer. Meth. Engng. 46, 131-150 (1999)

10. Nazari A., Mohandesi J.: Simulation of impact energy in functionally graded steels, Comp. Mater. Sci. 50, 1187-1196 (2011)

11. Needleman A., Tvergaard, V.: An Analysis of Ductile Rupture in Notched Bars. J. Mech. Phys. Solids 32, 461-490 (1984)

12. Ruzicka J., Spaniel M., Prantl A., Dzugan J., Kuzelka J., Moravec M.: Identification of Ductile Damage Parameters in the Abaqus. Bull. App. Mech. 8, 89-92 (2012)

13. Seabra M.R.R., Cesar de Sa J.M.A., Šuštarič P., Rodič T.: Some numerical issues on the use of XFEM for ductile fracture. Comput. Mech. 50, 611-629 (2012)

14. Seabra M.R.R., Cesar de Sa J.M.A., Šuštarič P., Rodič T.: Damage driven crack initiation and propagation in ductile metals using XFEM. Comput. Mech. 52,161-179 (2013)

15. Sun M., Packer J.A.: Charpy V-notch impact toughness of cold-formed rectangular hollow sections, J. Constr. Steel Res. 97, 114-126 (2014)

16. Tvergaard V.: On localization in ductile materials containing spherical voids. Int. J. Fract. 18, 237-252 (1980)

17. Xue Z., Pontin M.G., Zok F.W., Hutchinson J.W.: Calibration procedures for a computational model of ductile fracture. Eng. Fract. Mech. 77, 492-509 (2010)

18. Zuo J., Sutton M.A., Deng X.: Basic Studies of Ductile Failure Processes and Implications for Fracture Prediction. Fatigue Fract. of Eng. M. 27, 231-243 (2003) 


\section{Table Captions}

Table 1 Parameters of GTN model used in simulations of notched specimens

Table 2 Parameters of XFEM model used in simulations of notched specimens 


\section{Figures Captions}

Figure 1. Shape and dimensions of dogbone specimens and notches

Figure 2. Geometry of all three notches and mesh used for GTN (a) and XFEM (b) simulations

Figure 3. Boundary conditions applied and axis of symmetry for (a) $20 \mathrm{~mm}$ specimen and (b) $40 \mathrm{~mm}$ specimen

Figure 4. (a) Schematic of impact loading simulations. (b) Finite-element 2D approximation with boundary conditions

Figure 5. Force-displacement curves for uniaxial tension of specimen without notch

Figure 6. (a) Stress patterns in XFEM in quasi-static and (b) dynamic conditions; (c) void concentrations in GTN in quasi-static and (d) dynamic conditions

Figure 7. Force-displacement curves (a) and (b) evolution of crack length for uniaxial tension of specimen with $\vee$-shape notch

Figure 8. Evolution of force (a) and crack length (b) in impact loading of specimens with V-shape notch

Figure 9. Crack shapes for impact loading of specimen with V-shape notch as predicted with GTN (a) and XFEM (b)

Figure 10. Force-displacement curves (a) and evolution of crack length (b) for uniaxial tension of specimen with U-shape notch

Figure 11. Evolution of force (a) and crack length (b) in impact loading of specimens with U-shape notch

Figure 12. Force-displacement curves (a) and normalised evolution of crack length (b) for uniaxial tension of specimen with square notch

Figure 13. Crack shape for uniaxial tension of specimen with square notch: (a) experimental result; (b) GTN; (c) XFEM

Figure 14. Evolution of force (a) and crack length (b) in impact loading of specimens with square notch. Crack shapes for impact loading: (c) GTN; (d) XFEM 

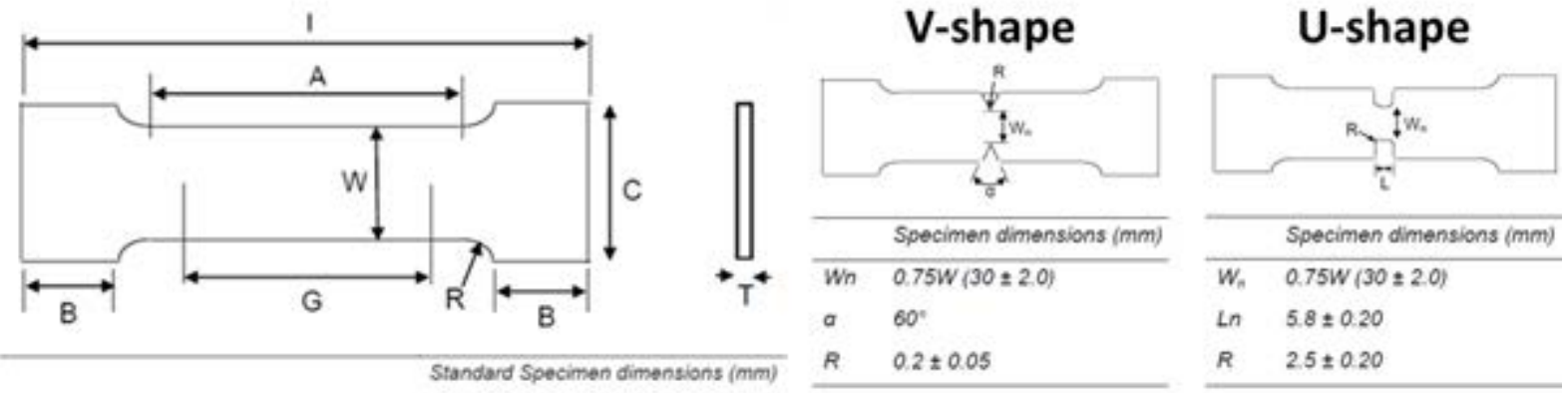

\begin{tabular}{ll}
\hline G-Gauge Length & 200 \\
W-Width & 40.0 \\
T-Thickness & 1 \\
R-Radius of Silet, min & 25 \\
L-Overall iength, min & 450 \\
A-Length of reduced section, min & 270 \\
B-Length of grip section, min & 75 \\
C-Width of grip section, approximate & 50
\end{tabular}

\section{Square-shape}

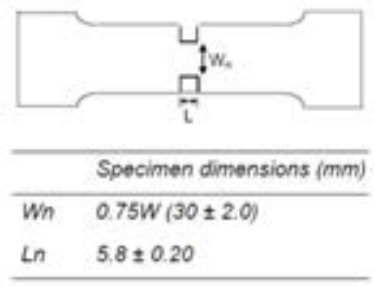

Figure 1. Shape and dimensions of dogbone specimens and notches 

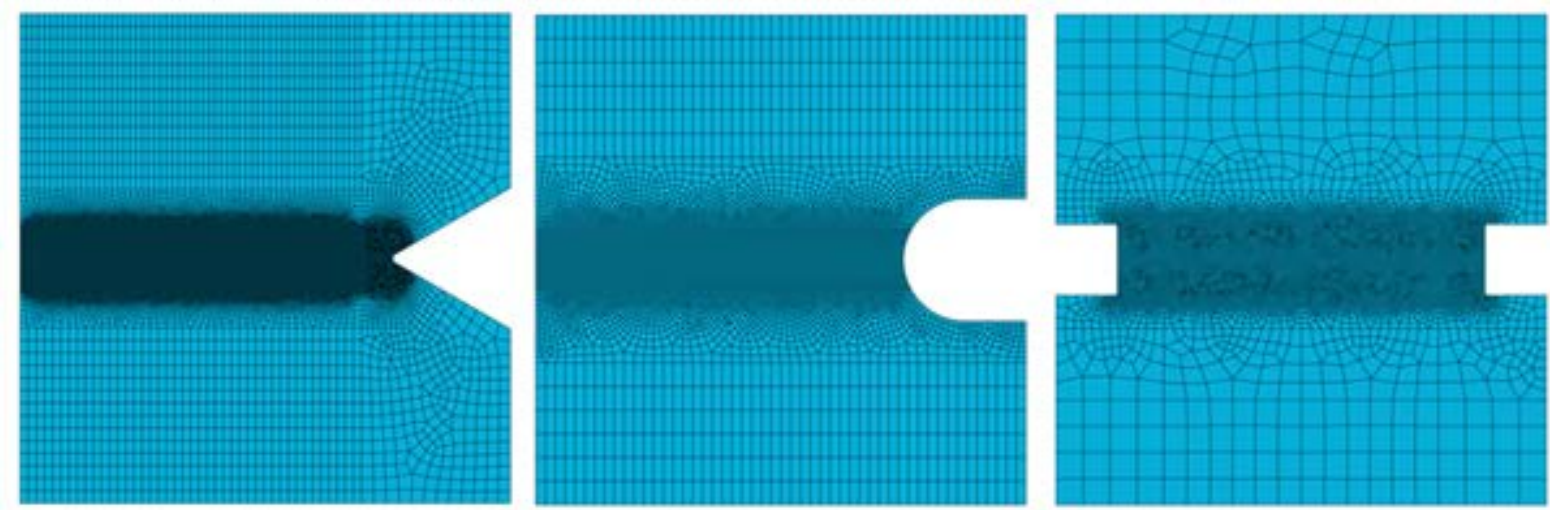

(a)
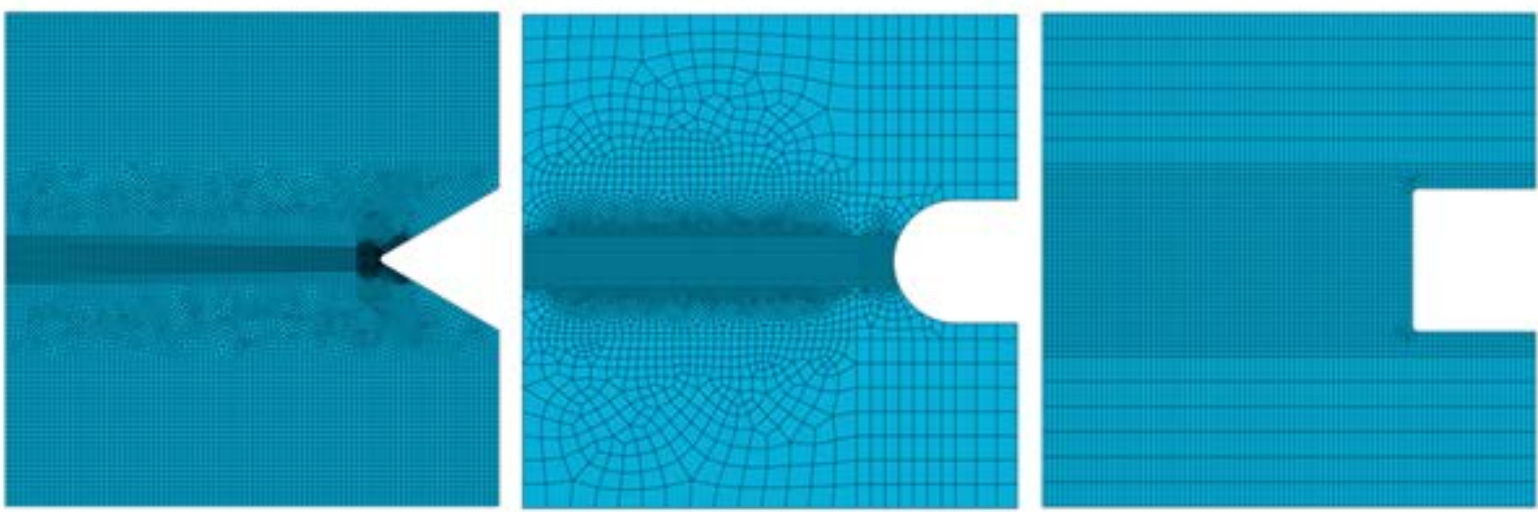

(b)

Figure 2. Geometry of all three notches and mesh used for GTN (a) and XFEM (b) simulations 

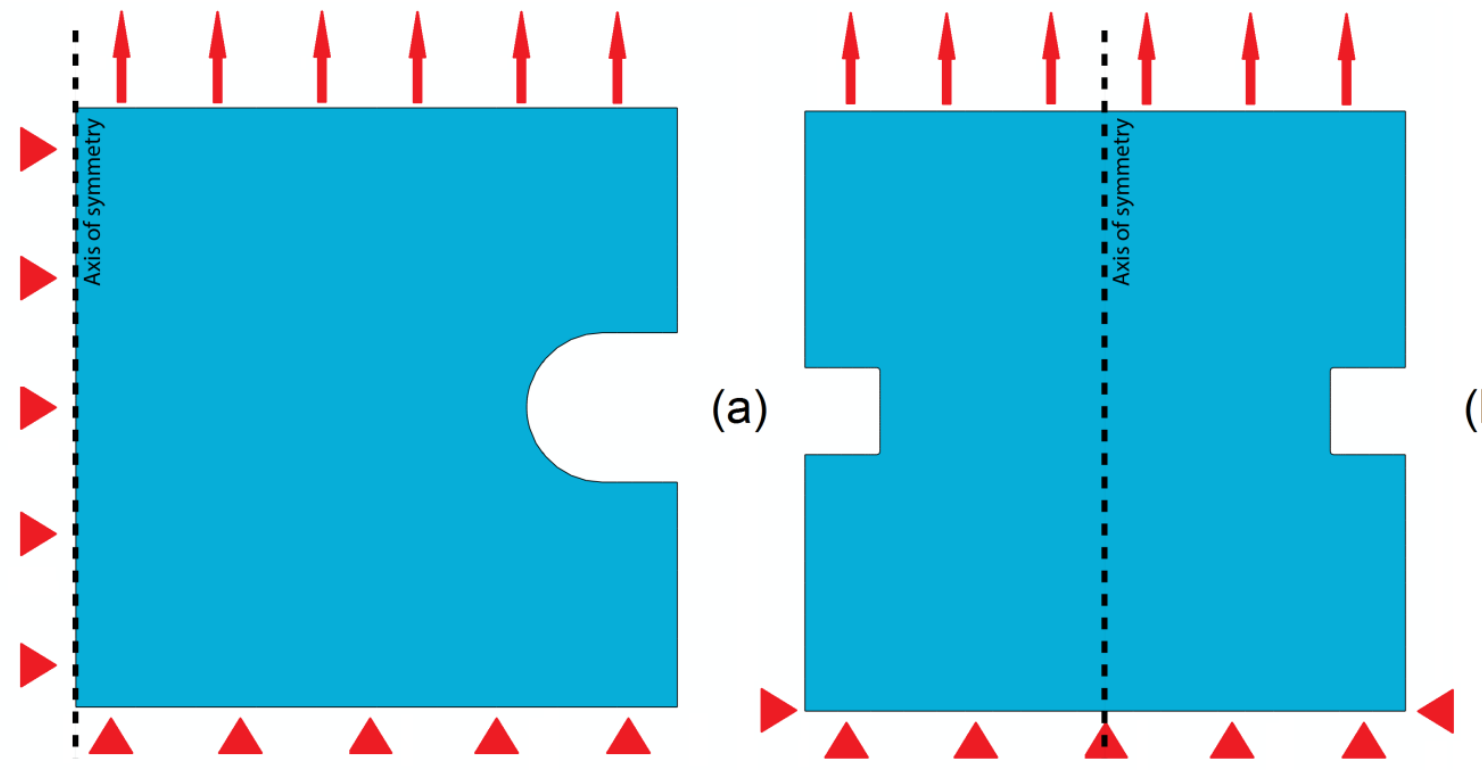

(b)

Figure 3. Boundary conditions applied and axis of symmetry for (a) $20 \mathrm{~mm}$ specimen and (b) $40 \mathrm{~mm}$ specimen 


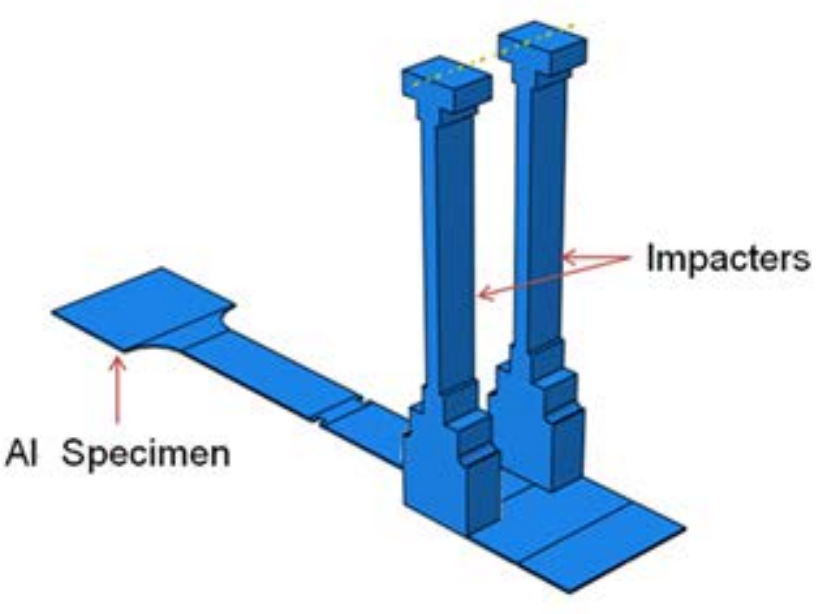

(a)

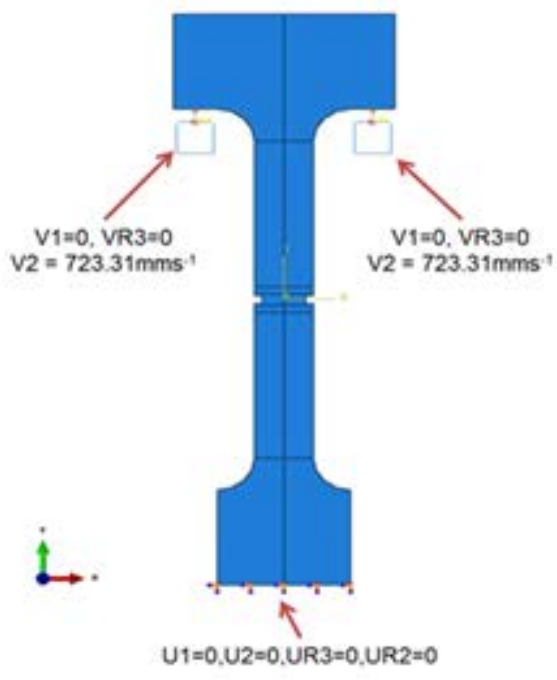

(b)

Figure 4. (a) Schematic of impact loading simulations. (b) Finite-element 2D approximation with boundary conditions 


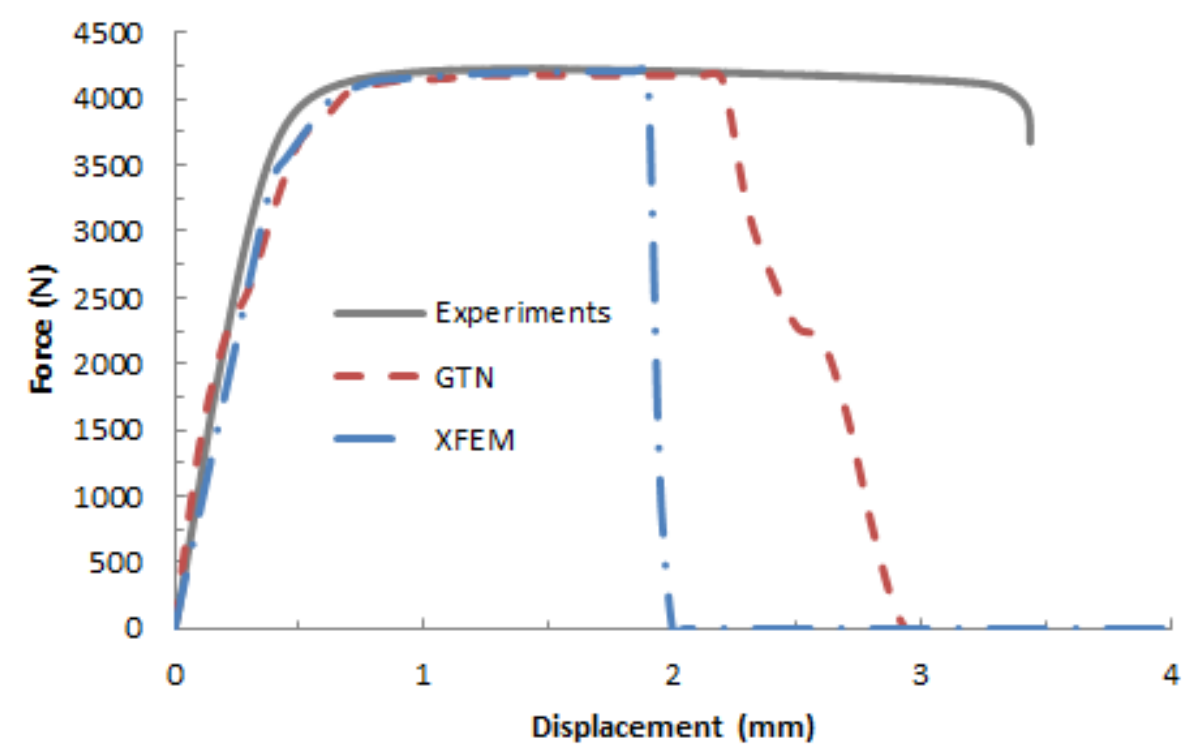

Figure 5. Force-displacement curves for uniaxial tension of specimen without notch 

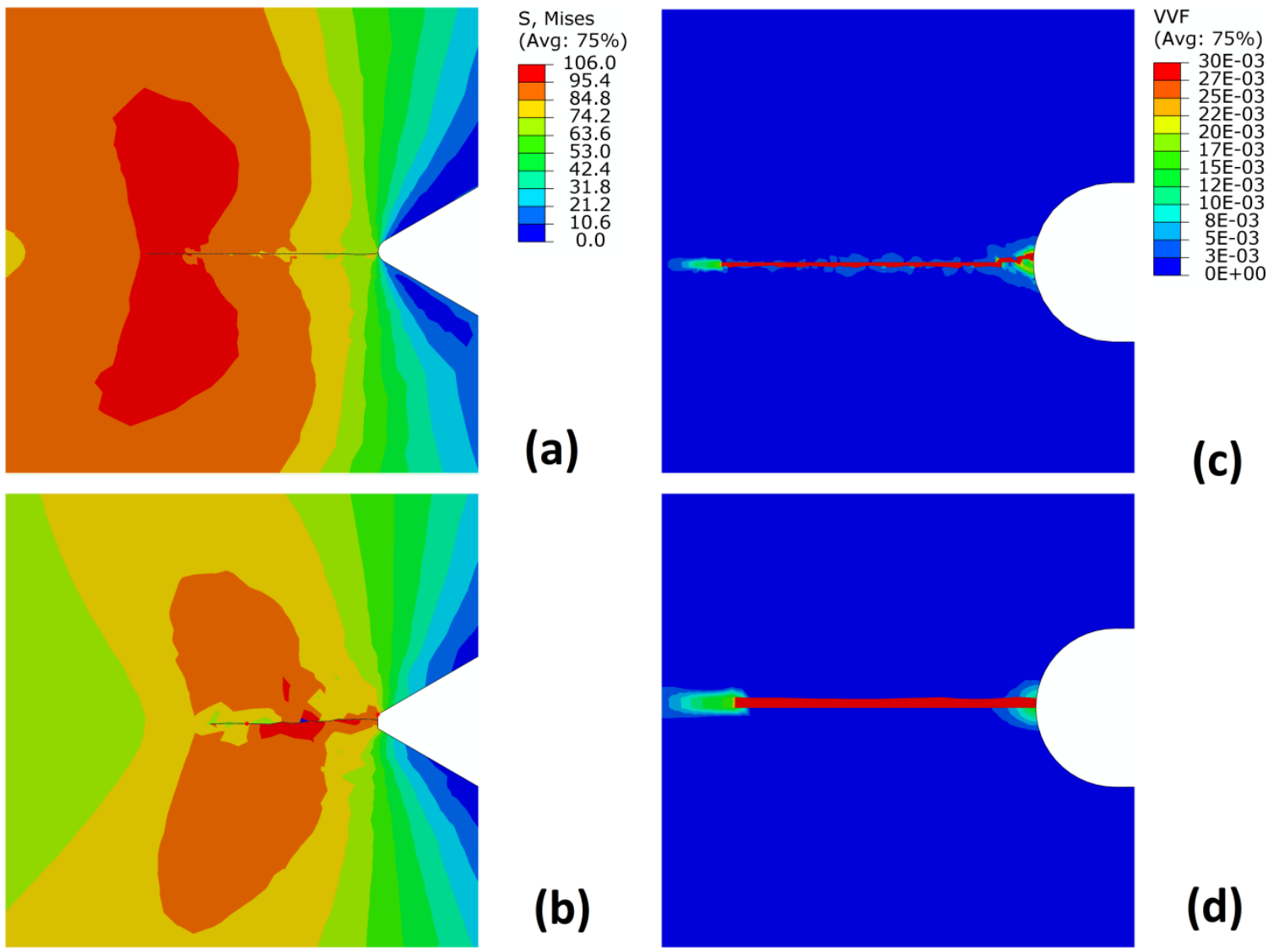

(c)

(b)

(d)

Figure 6. (a) Stress patterns in XFEM in quasi-static and (b) dynamic conditions; (c) void concentrations in GTN in quasi-static and (d) dynamic conditions 


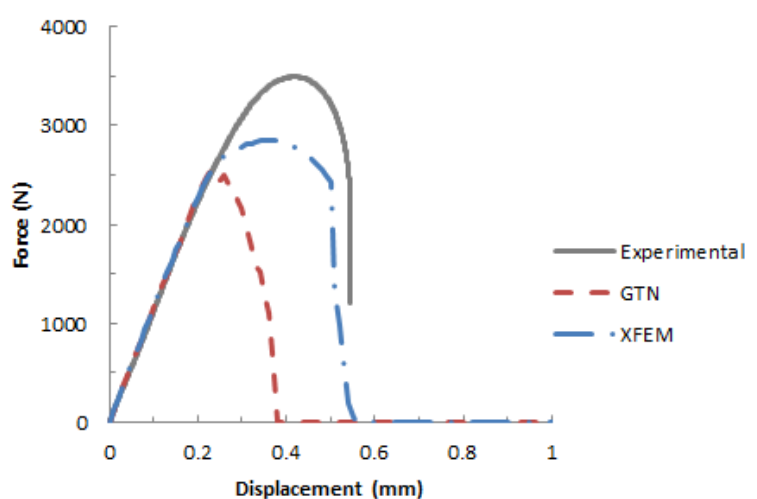

(a)

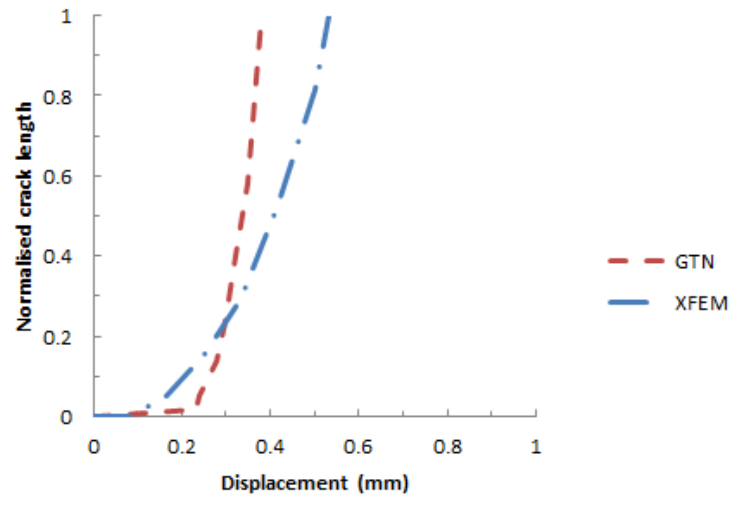

(b)

Figure 7. Force-displacement curves (a) and (b) evolution of crack length for uniaxial tension of specimen with $\mathrm{V}$-shape notch 


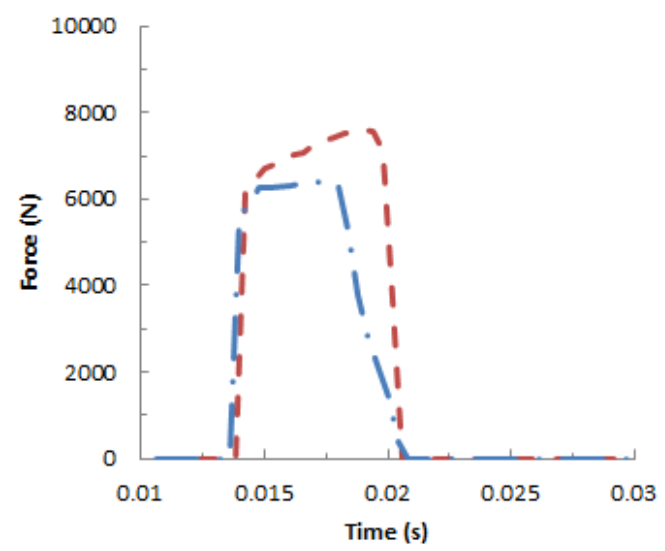

(a)

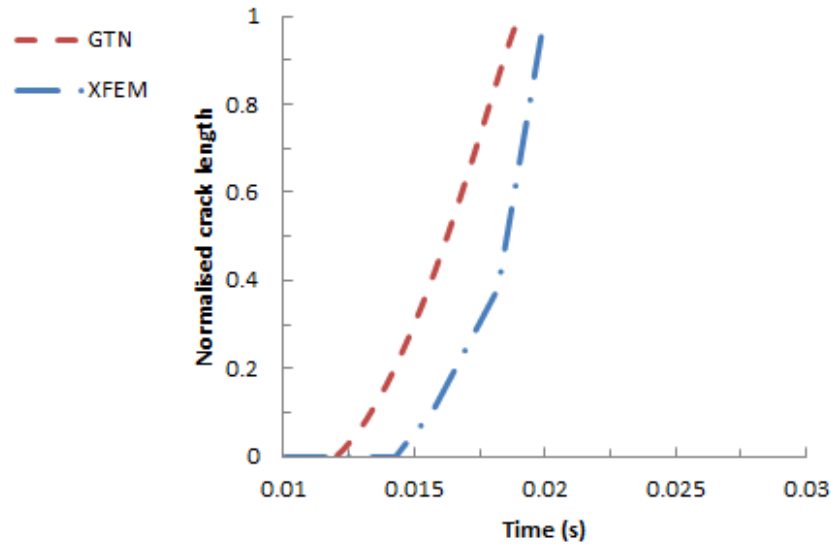

(b)

Figure 8. Evolution of force (a) and crack length (b) in impact loading of specimens with V-shape notch 


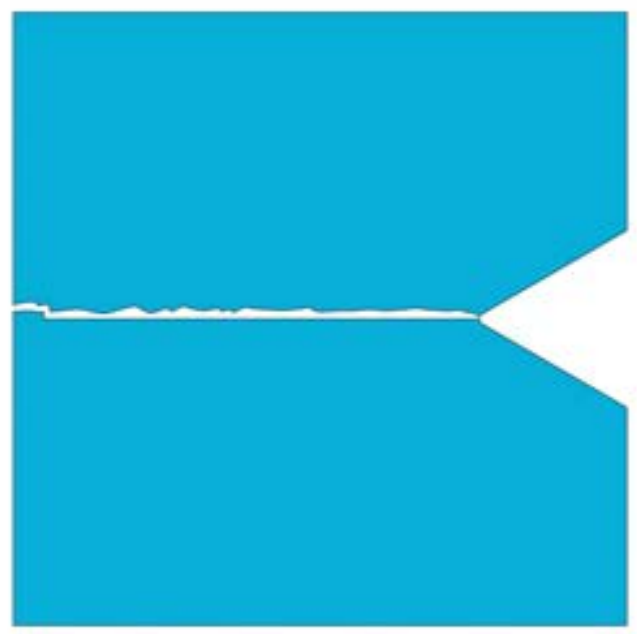

(a)

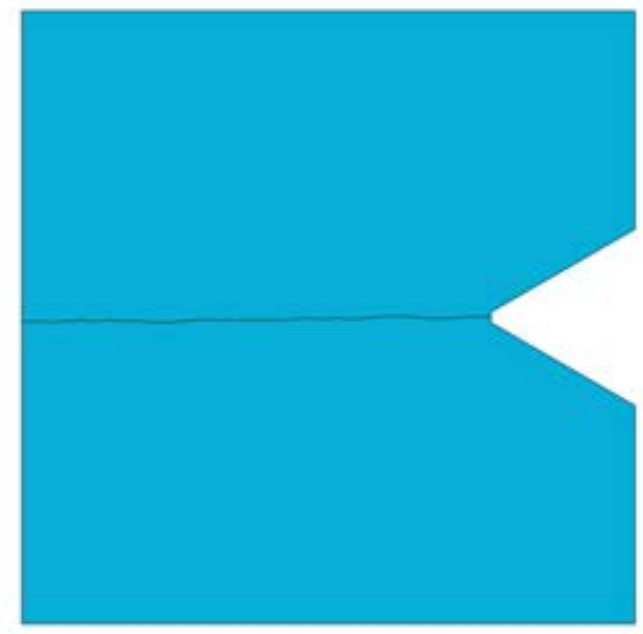

(b)

Figure 9. Crack shapes for impact loading of specimen with V-shape notch as predicted with GTN (a) and XFEM (b) 


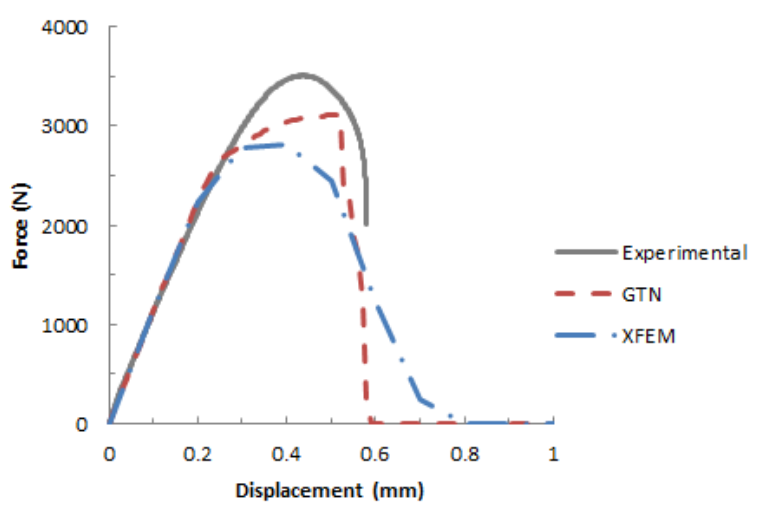

(a)

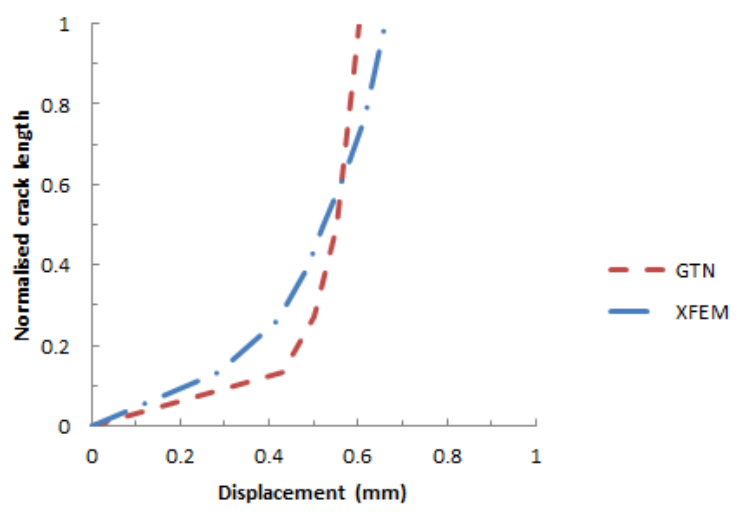

(b)

Figure 10. Force-displacement curves (a) and evolution of crack length (b) for uniaxial tension of specimen with U-shape notch 


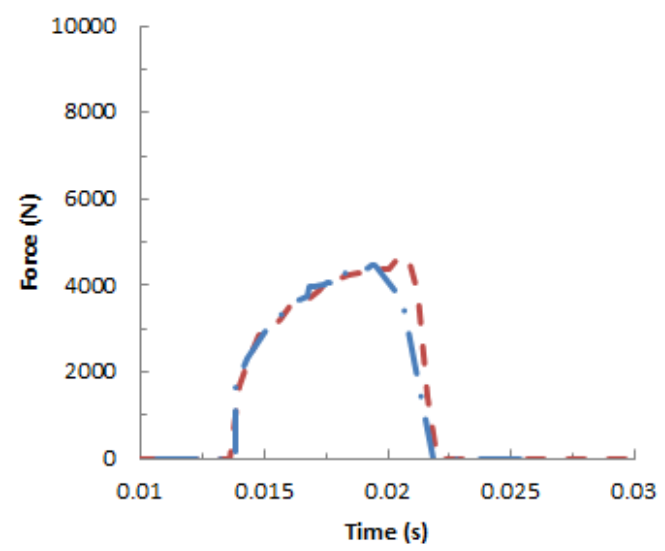

(a)

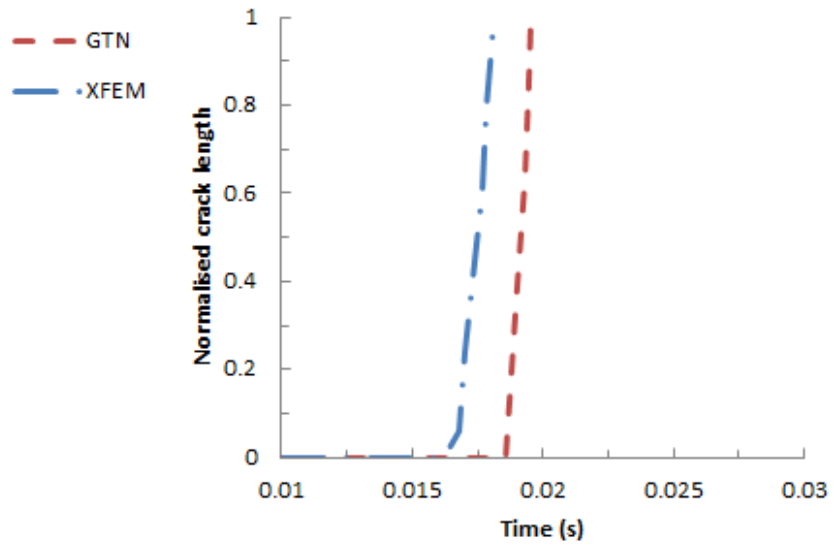

(b)

Figure 11. Evolution of force (a) and crack length (b) in impact loading of specimens with U-shape notch 


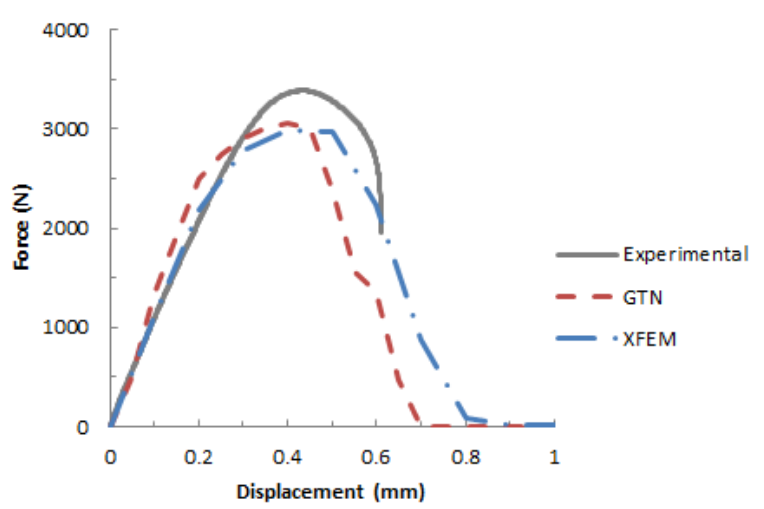

(a)

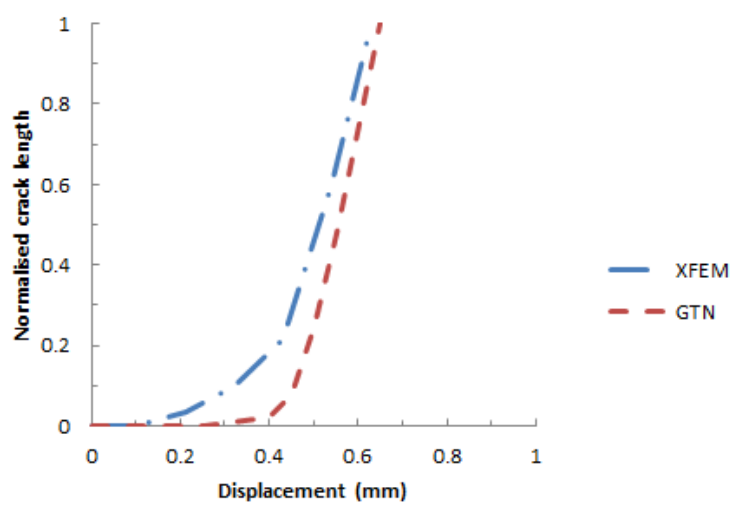

(b)

Figure 12. Force-displacement curves (a) and normalised evolution of crack length (b) for uniaxial tension of specimen with square notch 


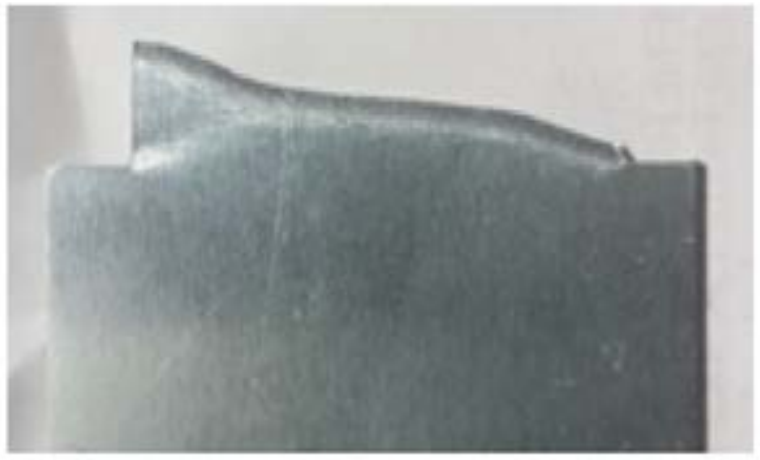

(a)

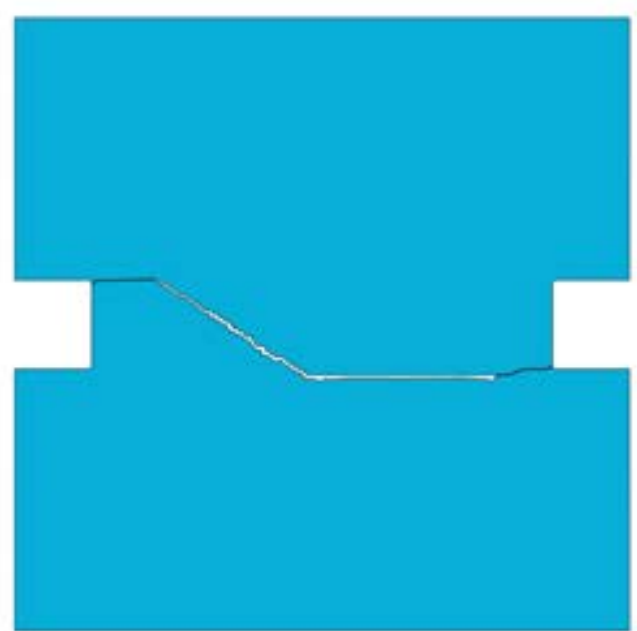

(b)

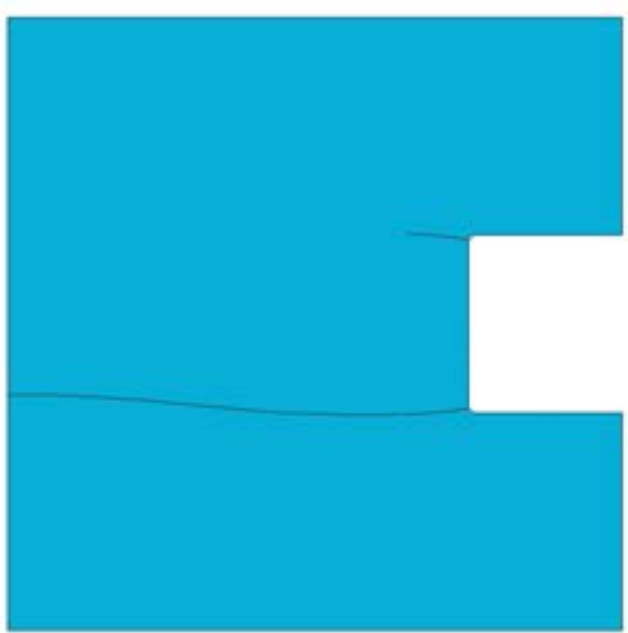

(c)

Figure 13. Crack shape for uniaxial tension of specimen with square notch: (a) experimental result; (b) GTN; (c) XFEM 


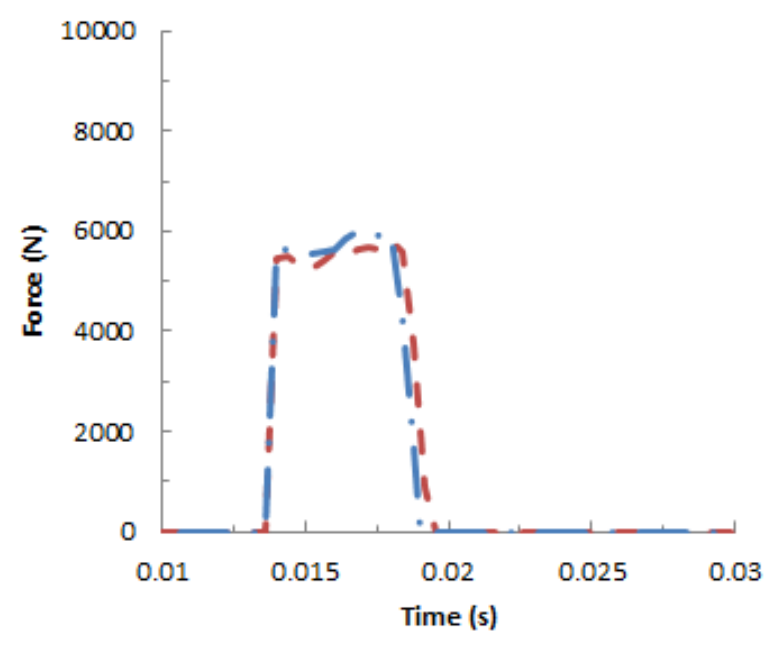

(a)

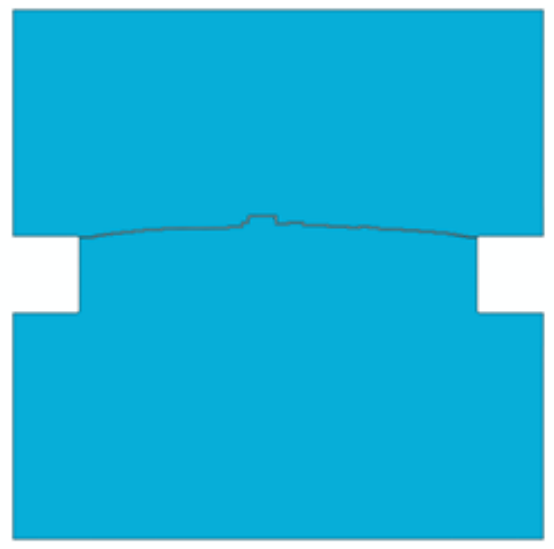

(c)

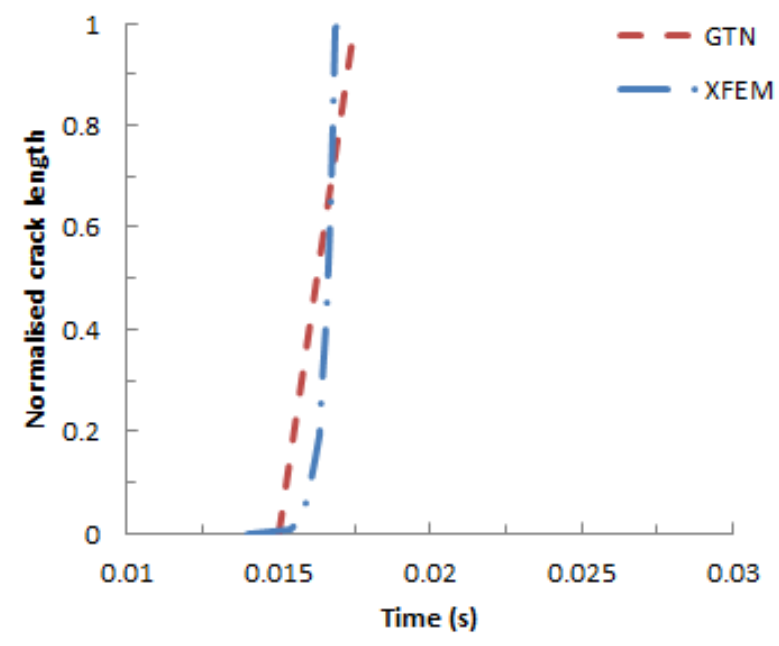

(b)

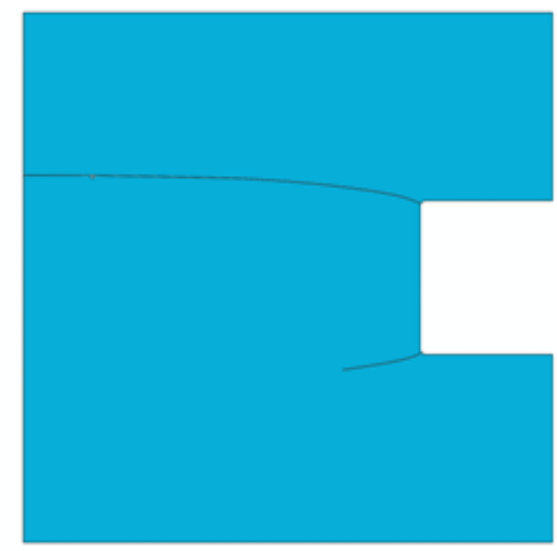

(d)

Figure 14. Evolution of force (a) and crack length (b) in impact loading of specimens with square notch. Crack shapes for impact loading: (c) GTN; (d) XFEM 